\title{
CITRUS HARVESTING BY VIBRATING ACTION
}

\author{
Mohamed I. Ghonimy ${ }^{1,3}$, Alzoheiry, A. M. ${ }^{2,3}$ and \\ Eid N. Abd El Rahman ${ }^{1}$
}

ABSTRACT

Mechanical harvesting of citrus by vibrating action depends on some parameters; frequency, amplitude and shaking time. The current study aimed to determine the optimum values of citrus performance parameters. The shaking machine was operated at three levels of frequency 2, $4 \& 6 \mathrm{~Hz}$, three levels of amplitude 50, $55 \& 60 \mathrm{~mm}$ and shaking time was $10 \mathrm{sec}$.

The results showed that the maximum fruit removal (FR) value, $99.1 \%$, was achieved at a frequency of $6 \mathrm{~Hz}$ and an amplitude equal to $60 \mathrm{~mm}$. this same frequency and amplitude also achieved the maximum ,100\%, degree of ripe-fruit selectivity $(\boldsymbol{D S})$.

The fruit removal percentage $(\boldsymbol{F R})$ and both frequency $(f)$ and amplitude (A) follows the equation:

$$
F R=100 \cdot\left(1-e^{-2.05 \times 10^{-3} \cdot f^{1.8} \cdot A^{1.2}}\right)
$$

In conclusion, it is recommended to use the frequency of $6 \mathrm{~Hz}$ and an amplitude equal to $60 \mathrm{~mm}$. The harvested fruits should be sorted to use the ripe fruits for fresh use and the rest of the fruits should be used for juice production.

Keywords: Citrus, Mechanical harvesting, Vibrating, Frequency, Amplitude.

\section{INTRODUCTION}

itrus harvesting is the most important operation among all production operations of citrus. Manual harvesting is considered a common method for citrus harvesting in Egypt. Late manual harvesting has many problems like low production rate and high cost. Mechanical vibration as an effective citrus harvesting method is capable of significantly reducing the labor costs and increasing the harvesting efficiency (Du et al. 2015).

1 Department of Agric. Eng., Faculty of Agriculture, Cairo University, Egypt 2 Dept. of Natural Resources and Agric. Eng., Faculty of Agric., Damanhour Univ., Egypt. 3 Dept. of Plant Production and Protection, Fac. of Agric. and Vet. Med., Qassim Univ., KSA. 
The mechanical harvesting of citrus (vibration method) depends on some parameters. Coppock and Hedden (1968) mentioned that the factors affecting the mechanical harvesting of tree fruits by shaking are Frequency, Eccentricity, the direction of shaking, fruit size, pull force to fruit weight ratio and fruit removal percentage. O'brien et al. (1986) mentioned that the high frequencies $(25-40 \mathrm{~Hz})$ and short amplitude (20 $-25 \mathrm{~mm}$ applied to primary limb) are generally most effective when tree structure and fruit attachment are relatively rigid. Long amplitude (100 $125 \mathrm{~mm}$ ) and low frequencies) $1.5-6 \mathrm{~Hz}$ ) have been found superior for willowy trees or trees with long branches that hang down under the mass of the fruits.

Brown (2002) used Stackhouse shaker heads designed for citrus harvesting, with an extended clamp area that enables the shaker to be placed on the major scaffold limbs when necessary. Fruit removal was in the range of 90 to $95 \%$, and the harvest rate was in the range of 50-to150 trees/h. Hong et al. (2012) minimized the severe damage of the Jatropha curcas trees while selectively harvesting by using an experimental canopy rotary drum shaker. The drum shaker had a series of straight fiberglass rods with an amplitude of $76.2 \mathrm{~mm}$ and frequency of $5 \mathrm{~Hz}$. Liu et al. (2017) used a series of shaking rods to study the vibrational acceleration spreads along the shaken branch. They found that the vibration was spreading from shaking spot to the stem and obviously increased. Whitney et al. (2001) found that the linear shaking patterns was better in fruit removal than the multidirectional shaking patterns. The linear shaking patterns with 6 to $7 \mathrm{~cm}$ displacement at $7 \mathrm{~Hz}$ frequency and a shaking time of 5 to $10 \mathrm{sec} /$ tree resulted in an orange removal percentage 1 to $6 \%$ higher than the multidirectional shaking pattern with the same displacement, frequency, and shaking time. A double-spiked-drum canopy shaker was developed by Peterson (1998), the shaker was equipped with twelve whorls and had 16 straight nylon rods distributed at an equal angle. The shaker removal average was $71 \%$ and $91 \%$ for shaking frequency of 4-5 Hz respectively.

This work aimed to determine the optimal level of performance parameters of citrus vibrating mechanical harvesting to obtain maximum both of fruit removal percentage and degree of ripe-fruit selectivity with minimum tree damage. 


\section{MATERIALS AND METHODS}

The experiments were conducted both in the laboratory and in the field.

\section{Laboratory measurements}

Some physical and mechanical properties of citrus fruit-stem system (Baladi Variety) were determined according to their maturity levels. Three maturity levels (ripe, half-ripe and green citrus fruits) were used. For each level, 20 citrus fruit-stem systems were randomly selected.

Fruit mass was measured using a digital balance (accuracy $1 \mathrm{~g}$ ). The detachment force of fruit $(\boldsymbol{F})$ from the stem was measured using digital force gauge (accuracy $=0.01 \mathrm{~N}$ ). In addition, length, diameter of citrusstem, and dimensions of citrus fruit were measured using a vernier caliper (accuracy of $0.1 \mathrm{~mm}$ ).

\section{Experimental tests}

Citrus branches were vibrated using a branch vibrator, fig. (1), which was designed by Ghonimy (1997). These branches were chosen in a critical stage of maturity (contains ripe, half-ripe and green citrus fruits). Nylon nets were fixed on a stands to collect the removed fruits.

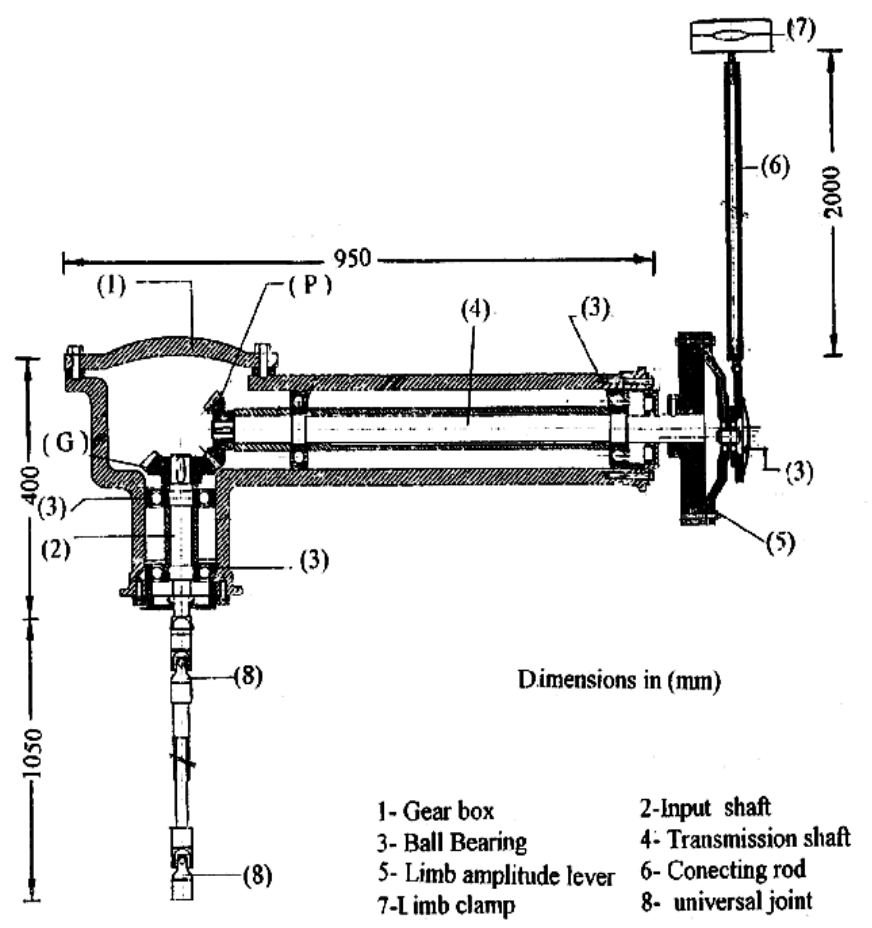

Fig. (1): Sectional plan of the used branch vibrator 
Baladi citrus variety branches are vibrated at three levels of frequency; 2, $4 \& 6 \mathrm{~Hz}$, three levels of amplitude; $50,55 \& 60 \mathrm{~mm}$ and $10 \mathrm{sec}$ of shaking time according to $O$ brien et al. (1986).

\section{Evaluating criteria}

\section{Fruit removal percentage $(F R)$}

$$
F R=\frac{N_{1}}{N_{2}} \times 100 \ldots \ldots \ldots \ldots \ldots \ldots \ldots
$$

Where:

$F R \quad=$ Fruit removal, \%;

$N_{1} \quad=$ Number of harvested citrus fruits from one branch;

$N_{2} \quad=$ The total number of citrus fruits on one branch.

\section{Degree of ripe-fruit selectivity $(D S)$}

$$
D S=\frac{N_{3}}{N_{4}} \times 100
$$

Where:

$D S \quad=$ Degree of ripe-fruit selectivity, $\%$.

N3 = Number of harvested ripe citrus fruits from one branch,

N4 = The total number of ripe citrus fruits from one branch.

\section{Branch damage at the point of contact with clamp of shaking} machine

The damage of tree branch at the point of contact with the clamp of the tree-vibrating machine was determined in terms of bruise volume of limb damage.

\section{RESULTS AND DISCUSSION}

The experiments were conducted both in the laboratory and in the field.

\section{Laboratory tests}

The results of detachment force of fruit, fruit mass and length and diameter of stem of citrus (Baladi variety) at different ripening stages are shown in table (1).

From table (1), it is clear that the detachment force of Baladi fruits decreased with the increasing of the maturity. A reduction of 6.4 to 21.8 $\%$ in the detachment force was observed with the increasing of maturity 
compared to the unripe stage. The fruit mass increased with the increasing of maturity, and the ratio between the detachment force and fruit mass $(\boldsymbol{F} / \boldsymbol{m})$ decreased with the increasing of the maturity. Meanwhile, the rate of changing of stem length and diameter were very small.

Table (2): Some physical properties of citrus (Baladi variety) and dimensional characteristics of stem at different ripening stages.

\begin{tabular}{|l|c|c|c|c|c|c|}
\hline \multirow{2}{*}{ Property } & \multicolumn{2}{|c|}{ Unripe } & \multicolumn{2}{c|}{ Half-ripe } & \multicolumn{2}{c|}{ Ripe } \\
\cline { 2 - 7 } & $\begin{array}{c}\text { Mean } \\
\text { value }^{(\mathbf{a})}\end{array}$ & $\mathbf{C V}^{(\mathbf{b})}$ & $\begin{array}{c}\text { Mean } \\
\text { value }^{(\mathbf{a})}\end{array}$ & $\mathbf{C V}^{(\mathbf{b})}$ & $\begin{array}{c}\text { Mean } \\
\text { value }^{(\mathbf{a})}\end{array}$ & $\mathbf{C V}^{(\mathbf{b})}$ \\
\hline $\begin{array}{l}\text { Fruit detachment } \\
\text { force }(F), \mathrm{N}\end{array}$ & $18.8 \mathrm{~A}$ & 9.66 & $17.6 \mathrm{~B}$ & 10.17 & $14.7 \mathrm{C}$ & 10.32 \\
\hline Fruit mass $(m), \mathrm{kg}$ & $0.138 \mathrm{~A}$ & 11.46 & $0.146 \mathrm{~B}$ & 14.65 & $0.148 \mathrm{~B}$ & 13.54 \\
\hline$F / m$, & 140.2 & 10.85 & 121.7 & 14.72 & 100.3 & 9.74 \\
\hline Stem length, mm & $25.2 \mathrm{~A}$ & 16.38 & $25.4 \mathrm{~A}$ & 17.37 & $25.3 \mathrm{~A}$ & 20.6 \\
\hline Stem diameter & $2.9 \mathrm{~A}$ & 8.22 & $3.0 \mathrm{~A}$ & 8.41 & $3.1 \mathrm{~A}$ & 7.56 \\
\hline
\end{tabular}

\section{Field experiments}

\subsection{Citrus fruit removal $(F R)$}

Vibration frequencies of 2,4 and $6 \mathrm{~Hz}$, amplitudes of vibration at the point of location of the vibrator of 50,55 and $60 \mathrm{~mm}$, and time of vibration of $10 \mathrm{sec}$ were selected for field experiments.

From Fig. (2) it is clear that the fruit removal percentage (FR) of citrus fruits increased by increasing of frequency from 2 to $6 \mathrm{~Hz}$ at all tested amplitude values.

The maximum $\boldsymbol{F R}, 99.1 \%$, was achieved at frequency $6 \mathrm{~Hz}$ and amplitude $60 \mathrm{~mm}$. While the minimum $\boldsymbol{F R}, 52.9 \%$, was found at frequency $2 \mathrm{~Hz}$ and amplitude $50 \mathrm{~mm}$. At $2 \mathrm{~Hz}$ frequency, the maximum $\boldsymbol{F R}, 61.7 \%$, was achieved at amplitude $60 \mathrm{~mm}$. At $4 \mathrm{~Hz}$ frequency, the maximum $\boldsymbol{F R}, 95.1 \%$, was achieved at amplitude $60 \mathrm{~mm}$. While, at $6 \mathrm{~Hz}$ frequency, the maximum $\boldsymbol{F R}, 99.1 \%$, was achieved at amplitude $60 \mathrm{~mm}$. Thus, it could be concluded that the $\boldsymbol{F} \boldsymbol{R}$ increased by increasing the frequency and amplitude. 


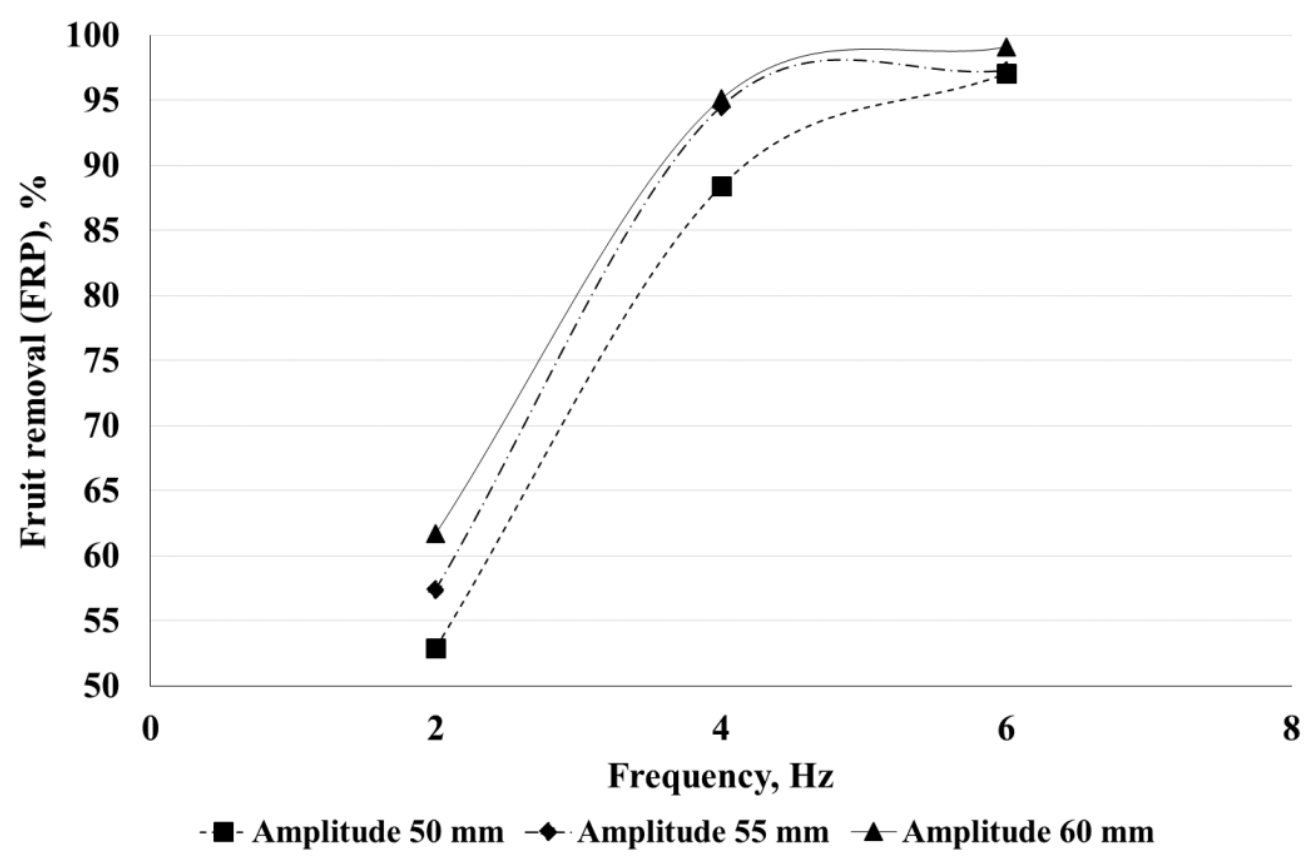

Fig. (2): Effect of frequency on the citrus removal percentage at different amplitudes

Referring to the processed data, the results showed that by increasing the amplitude for the same frequency, the fruit removal percentage was increased by a percentage ranged from 2 to $9 \%$.

The relationship between fruit removal percentage with frequency and amplitude are shown in equation (3). (According to O brien et al. 1986).

$$
F R=100 \cdot\left(1-e^{-k \cdot f^{\alpha} \cdot A^{\beta}}\right)
$$

Where:

$$
\begin{aligned}
F R & =\text { Fruit removal } & , \% ; \\
F & =\text { Frequency } & , \mathrm{Hz} ; \\
A & =\text { Amplitude } & , \mathrm{mm} ; \\
k, \alpha \text { and } \beta & =\text { Coefficients. } &
\end{aligned}
$$

To determine the values of the experimental constants $(k, \alpha$ and $\beta)$ for citrus crop, the following step derivation had to be performed: 
1. Experimental constants have to be in one side of the equation (3) as follows:

$$
\begin{gathered}
\frac{F R}{100}=\left(1-e^{-k \cdot f^{\alpha} \cdot A^{\beta}}\right) \\
e^{k \cdot f^{\alpha} \cdot A^{\beta}}=\left(1-\frac{F R}{100}\right)^{-1}
\end{gathered}
$$

2. changing the exponential equation to linear equation by taking the natural exponent logarithm two times as follow:

$$
\ln k+\alpha \ln f+\beta \ln A=\ln \left(-\ln \left(1-\frac{F R}{100}\right)\right)
$$

Then,

$$
n \ln k+\alpha \sum \ln f+\beta \sum \ln A=\sum \ln \left(-\ln \left(1-\frac{F R}{100}\right)\right) \ldots
$$

Using the obtained data from the field experiments (figure 2), equation (4) was solved to determine the values of experimental constants. After the solution of equation, the values of constants were obtained as:

$$
k=2.05 \times 10^{-3}, \alpha=1.8, \beta=1.2
$$

The relationship between fruit removal percentage and both frequency and amplitude could be represented as exponential function in the following form (equation 5):

$$
F R=100 \cdot\left(1-e^{-2.05 \times 10^{-3} \cdot f^{1.8} \cdot A^{1.2}}\right)
$$

The comparison between the average values of fruit removal percentage and predicted fruit removal percentage (from equation 5) is shown in fig. (3). It's clear that the actual fruit removal is very close to the predicted values for the same frequency and amplitude. Thus the equation with the determined constants can be used for the selection of the optimum 
performance parameters (frequency, amplitude and shaking time) with multi-criteria of highest fruit removal at minimum limb damage.

\subsection{Ripe-fruit degree of selectivity $(D S)$}

The average values of fruit degree of selectivity $(\boldsymbol{D S})$ for ripe citrus fruits are shown in Fig. (4). It is clear that the values of $\boldsymbol{D S}$ for the same frequency were increased by increasing the amplitude. The minimum value of $\boldsymbol{D S}$ was $70.7 \%$ at $2 \mathrm{~Hz}$ of frequency and $50 \mathrm{~mm}$ of amplitude. While, the maximum value of $\boldsymbol{D S}$ was $100 \%$ at $6 \mathrm{~Hz}$ of frequency and 60 mm of amplitude.

The increase in the $\boldsymbol{D S}$ values with the increase of the amplitude or the frequency can be attributed to the decrease in the $(\boldsymbol{F} / \boldsymbol{m})$ ratio (Table 1) because the more the fruit rips its' required detachment force decreases and its' mass increases.

From figures (2) and (4) it is clear that the maximum $\boldsymbol{F R}, 99.1 \%$, was achieved at $6 \mathrm{~Hz}$ frequency and $60 \mathrm{~mm}$ amplitude. The maximum $\boldsymbol{D S}$, $100 \%$, was achieved at the same frequency and amplitude.

\subsection{Branch damage at the point of contact with the clamp of vibrating} machine

Although, in all tested frequencies and amplitudes, there was no damage to the branches at the point of contact to the clamp, however, very slight and rare bruising may occur in the main branches. These bruising which may affect the phloem could stimulate reproductive growth. When downward phloem translocation of carbohydrates and growth hormones is blocked by scoring, these compounds tend to diffuse into the xylem and are transported upward in the transpiration stream and concentrate in the leaves and tissues involved in reproduction. Moreover, bruising and griddling affect positively the plant hormone "ethylene" which in turn stimulates the induction of the floral buds and ultimately improve flowering in the following season and increase fruit yield. The increase in flower initiation following possible phloem blockage due to vibrating action usually is evident in the season following treatment (Schulte et al. 1992). 

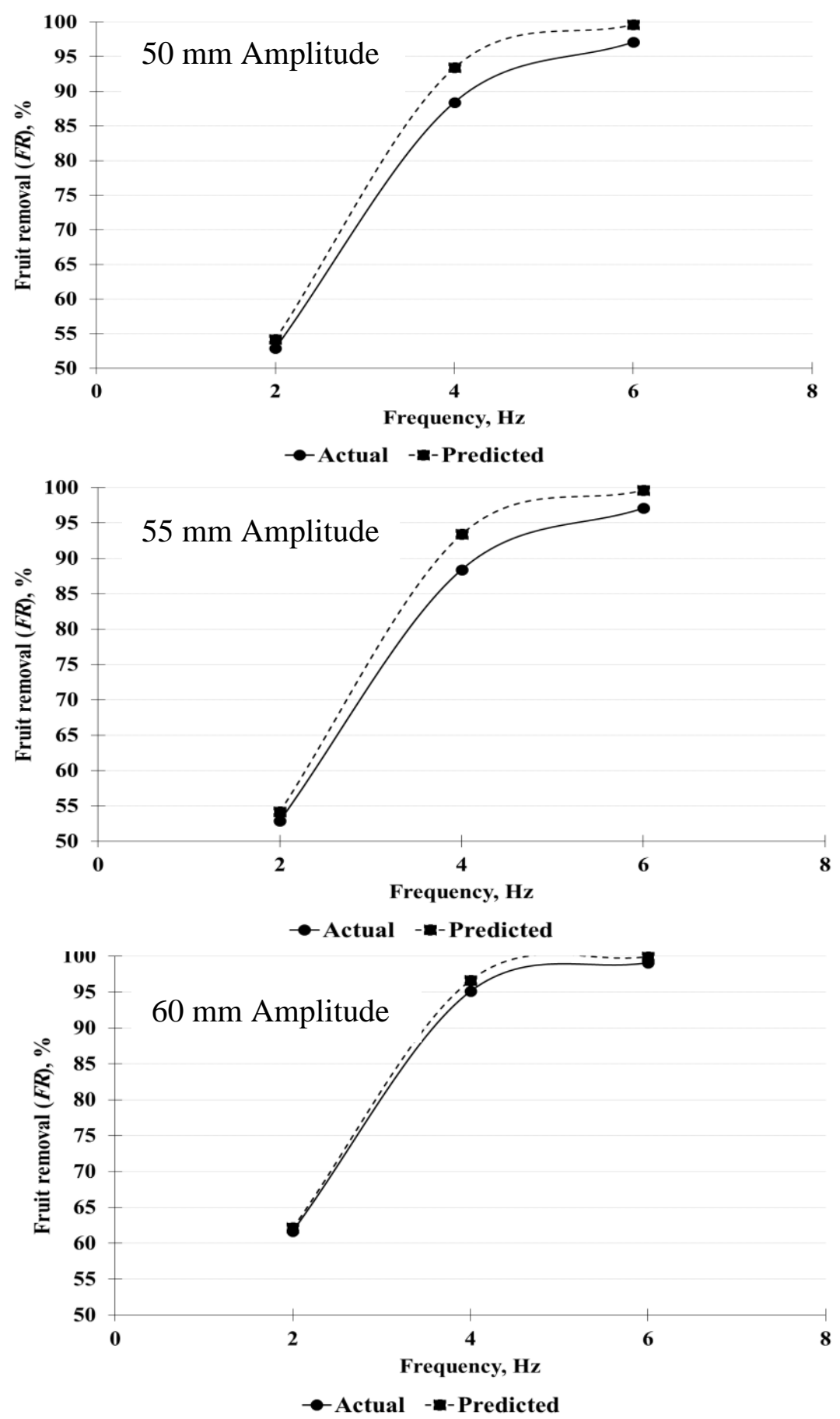

Fig. (3): Actual and predicted citrus removal percentage at different frequencies and amplitudes. 


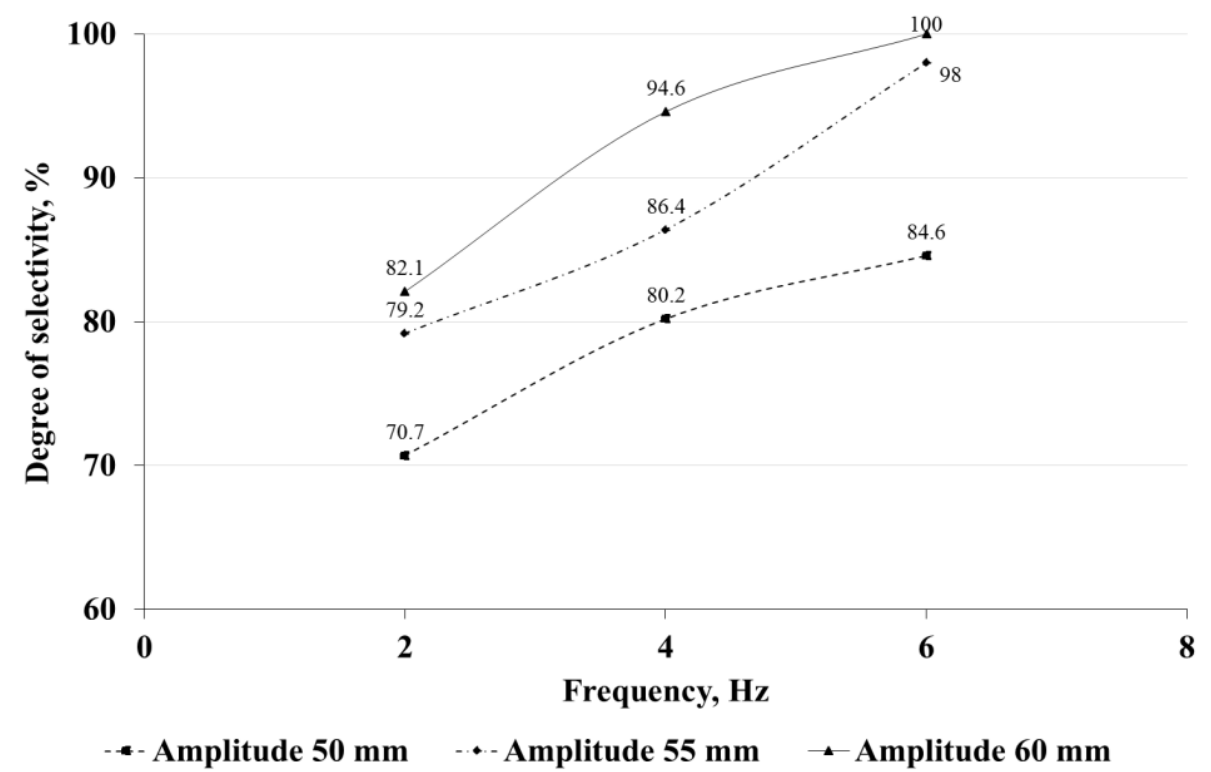

Fig. (4): Degree of selectivity of ripe-citrus fruits as function of amplitude and frequency.

\section{CONCLUSION}

From this investigation, the following conclusion can be made:

1. The ratio between the detachment force and fruit mass $(\boldsymbol{F} / \boldsymbol{m})$ decreased with increasing the maturity.

2. The maximum value of fruit removal $(\boldsymbol{F R}), 99.1 \%$, was achieved at frequency $6 \mathrm{~Hz}$ and amplitude $60 \mathrm{~mm}$.

3. The maximum value of degree of selectivity $(\boldsymbol{D S})$ was $100 \%$ at $6 \mathrm{~Hz}$ of frequency and $60 \mathrm{~mm}$ of amplitude.

4. For all tested frequencies and amplitudes there were no damage on the branches at the point of contact of the clamp.

In conclusion, it is recommended to use the frequency of $6 \mathrm{~Hz}$ and an amplitude equal to $60 \mathrm{~mm}$. The harvested fruits should be sorted to use the ripe fruits for fresh use and the rest of the fruits should be used for juice production 


\section{REFERENCES}

Brown, G. K. (2002). Citrus harvesting program update for the 2000-2002 seasons. Florida Department of Citrus. Lakeland, FL 3302-0148. http://www.fdocitrus.com/

Coppock, G. E. and Hedden, S. L. (1968). Design and development of tree shaker harvest system for citrus fruits. Transactions of the ASAE, 11 (3): 339 - 347.

Du, X. Q., Wu, C. Y., He, L. Y., and Tong, J. H. (2015). Dynamic characteristics of dwarf Chinese hickory trees under impact excitations for mechanical fruit harvesting. Int. J. Agric. Biol. Eng., 8(1): 17-25.

Ghonimy, M. I. (1997). Design and Evaluation of Olives Harvesting Machine by Shaking. Ph.D., Faculty of Agric., Cairo University.

Hong, M. Y., Rosa, U. A., and Upadhyaya, S. K. (2012). Optimum operating parameters for a rotary drum shaker for harvesting jatropha curcas L. Transactions of the ASABE, 55(6): 2051-2058

Liu, T. H., Ehsani, R., Toudeshki, M., Zou, X. J., and Wang, H. J. (2017). Experimental study of vibrational acceleration spread and comparison using three citrus canopy shaker shaking tines. Shock \& Vibration, 1: 1-9.

O`brien, M., Cargill, B. F. and Fridley, R.B. (1986). Principals and Practices for Harvesting and Nuts. AVI bub. Comp, INC., Westport, Connecticut.

Peterson, D. (1998). Mechanical harvester for process oranges. Applied Engineering in Agriculture, 14(5): 455-458.

Schulte, N. L., Brown, G. K. and Timm, E. J. (1992). Apple Impact Damage Thresholds. Applied Engineering in Agriculture 8(1):5560 .

Whitney, J. D., BenSalem, E. and Salyani, M. (2001). The effect of trunk shaker patterns on Florida orange removal. Applied Engineering in Agriculture ASAE 17(4): 461-464. 


\section{الملخص العربي \\ حصاد الموالح باستخدام أسلوب الهزي}

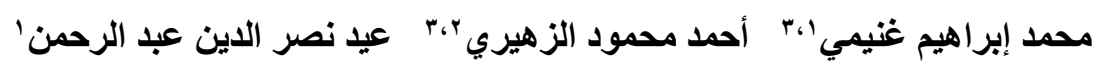

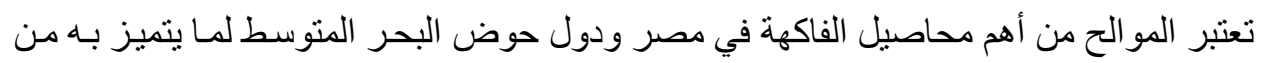

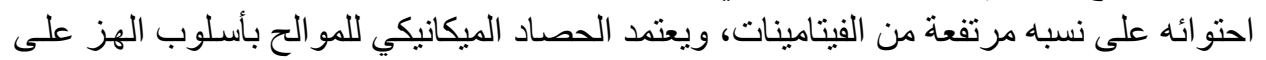

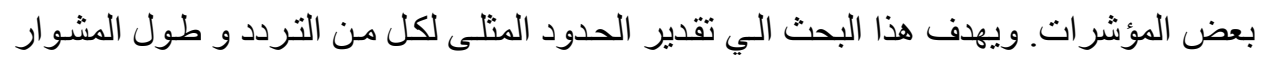

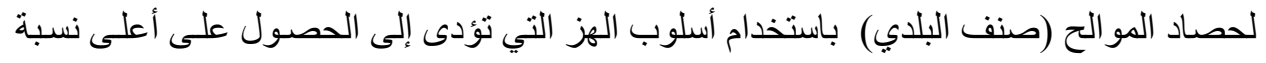

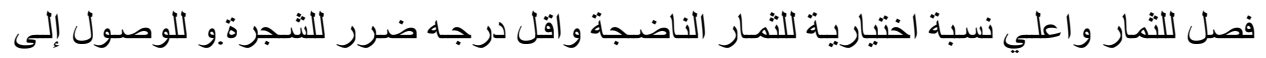

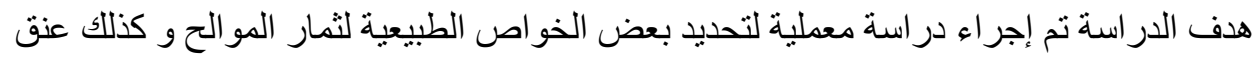

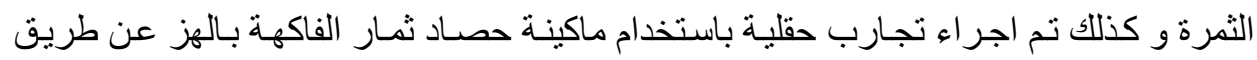

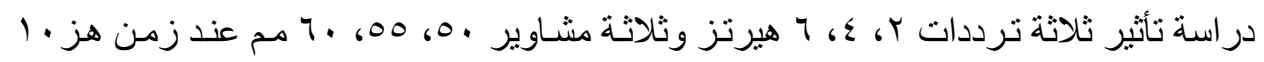

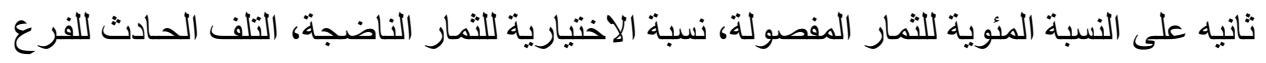

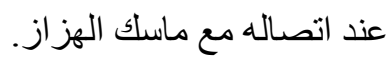

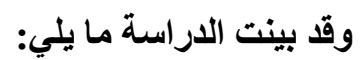
ا. . تقل النسبة بين القوة اللازمة للفصل وكتلة الثمرة للبرتقال (صنف البلدي) بزيادة درجـة

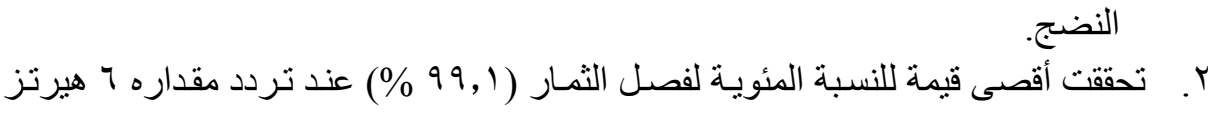
وطول مشوار • . 7 مم.

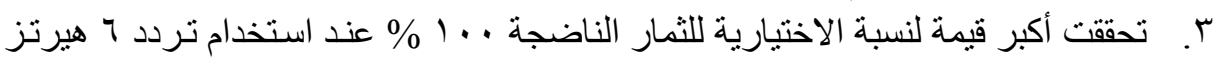

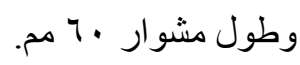

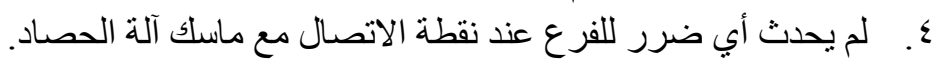

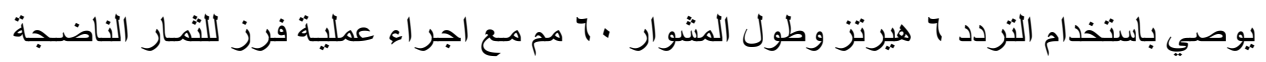

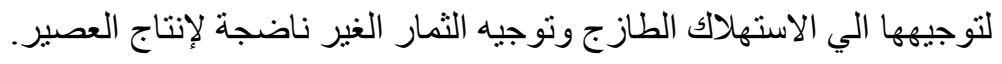

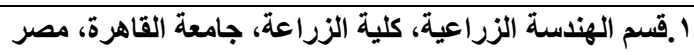

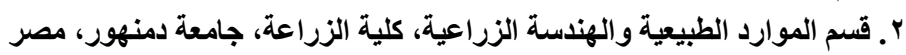

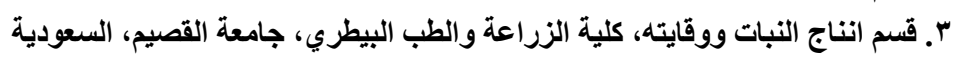

